\title{
Properties of tungsten mine waste geopolymeric binder
}

\author{
Fernando Pacheco-Torgal $^{\text {a,* }}$, João Castro-Gomes ${ }^{\text {b,1 }}$, Said Jalali ${ }^{c, 2}$ \\ ${ }^{a}$ Castelo Branco Polytechnic Institute, Department of Civil Engineering, 6000 Castelo Branco, Portugal \\ ${ }^{\mathrm{b}}$ University of Beira Interior, Department of Civil Engineering, 6200 Covilhã, Portugal \\ ${ }^{\mathrm{c}}$ University of Minho, Department of Civil Engineering, 4800 Guimarães, Portugal
}

Received 18 October 2006; received in revised form 29 December 2006; accepted 31 January 2007

Available online 21 March 2007

\begin{abstract}
Tungsten mine waste mud (TMWM) geopolymeric binder is a new cementitious material with a very high early age strength. It is obtained from dehydroxylated mine waste powder mix with minor quantities of calcium hydroxide and activated with $\mathrm{NaOH}$ and waterglass solutions. Tests on properties of TMWM binders such as workability, setting time, unrestrained shrinkage, water absorption and static modulus of elasticity were carried out and the results are reported in this paper. This is followed by comparisons with literature related data and a discussion about it. The results showed that current devices use to assess OPC fresh properties are not recommended to evaluate TMWM binders. It has also been found that traditional procedures used to evaluate unrestrained shrinkage may be responsible for misleading results when using those new binders. Water absorption data shows that TMWM has a very compacted structure. Results concerning the static modulus of elasticity are similar to the ones obtained by other authors. However the hypothesis related to modulus of elasticity decrease due to the use of high $\mathrm{Al} / \mathrm{Si}$ alkali activated mixtures was not confirmed.
\end{abstract}

(C) 2007 Elsevier Ltd. All rights reserved.

Keywords: Geopolymeric binder; Tungsten mine waste mud; Workability; Setting time; Shrinkage; Water absorption; Static modulus of elasticity

\section{Introduction}

Studies of alkali-activated cements have a long history in the former Soviet Union, Scandinavia, and Eastern Europe [1]. In 1978, Davidovits created the term "geopolymer", to characterise new materials with the ability to transform, polycondense and adopt a shape rapidly at low temperatures like "polymers" [2]. The polymerisation process involves a chemical reaction under highly alkaline conditions on $\mathrm{Al}$ $\mathrm{Si}$ minerals yielding polymeric $\mathrm{Si}-\mathrm{O}-\mathrm{Al}-\mathrm{O}$ bonds with empirical formula $\mathrm{Mn}\left[-\left(\mathrm{Si}-\mathrm{O}_{2}\right) z-\mathrm{Al}-\mathrm{O}\right] n$. $\mathrm{wH}_{2} \mathrm{O}$, where $n$ is the degree of polymerization, $z$ is 1,2 or 3 , and $M$ is an alkali cation, such as potassium or sodium [3]. Davidovits

\footnotetext{
* Corresponding author. Tel.: +351272 339300; fax: +351 272339399.

E-mail addresses: fernandotorgal@est.ipcb.pt (F. Pacheco-Torgal), castro.gomes@ubi.pt (J. Castro-Gomes), said@civil.uminho.pt (S. Jalali).

${ }^{1}$ Tel.: +351 275 329990; fax: +351 275329969 .

${ }^{2}$ Tel.: +351 253 510200; fax: +351253510213.
}

reported several advantages of geopolymeric cementitious systems over Portland cement mainly environmental, due to the fact that geopolymeric based concrete has a much longer service life than Portland cement based ones, to the metals waste encapsulation capacity and to lower $\mathrm{CO}_{2}$ emissions [4]. The geopolymerization requires a precursor that contains significant quantities of silicon and aluminium held in an amorphous phase such as ashes from power stations or mining and quarrying wastes.

Over the last years several authors have reported research in a large number of aspects related to geopolymeric based binders such as: dependence of the nature on source materials (geopolymers synthesised from calcined sources show a higher compressive strength than from raw materials) [5-7], immobilization of toxic metals [8,9], reaction mechanisms and hydration products $[10-13]$, the role of calcium in geopolymerization [14-17], manufacture operations $[18,19]$ and even the development of lightweight building materials[20]. 
However, there is little research published, about geopolymeric binders synthesized from mine and quarry wastes. Studies concerning the geopolymerization of different minerals suggest that a wide range of Al-Si based minerals could be used as source precursors [5]. However one should notice that those studies used high purity geological specimens, so mine waste mineral will hardly behave just like it.

Panasqueira is an underground mine situated in central Portugal on the southern edge of the Sierra da Estrela mountain range, a natural park, near the Sierra do Açor, a protected landscape, and also near the Zezere river. Tungsten and tin have been mined in the Panasqueira area since the 1890s. During the mining process two types of mine waste are generated, coarse aggregates derived from rock blasting and waste mud conveyed by pipelines into lagoons amounting for several million tonnes and still generating almost 100 tonnes per day. Previous studies concerning the alkali-activation of TMWM together with a small percentage of calcium hydroxide suggests that a geopolymeric binder with extremely high early age strength can be produced $[21,23]$. This paper reports the experimental results on some physical and mechanical properties of TMWM binders.

\section{Experimental work}

\subsection{Materials}

TMWM used in this study was subject to a thermal treatment at $950{ }^{\circ} \mathrm{C}$ during $2 \mathrm{~h}$, in order to achieve the dehydroxylated state. Mineralogical composition and thermal conditions were described elsewhere [24].The XRD patterns indicated that mine waste mud consists mainly of muscovite and quartz which were identified by their characteristic patterns as follows: muscovite (card $46-$ 1409) and quartz (card 46 - 1045). For those thermal conditions XRD patterns indicated that dehydroxylation did not result in a complete collapse of muscovite structure. Calcination leads to formation of an amorphous phase, causing an increase in the general background (BG) of XRD patterns and dominantly taking place in the calcinations interval from 850 to $950{ }^{\circ} \mathrm{C}$, with a thermal behaviour similar to other phyllosilicate clay minerals. The main muscovite peak $\left(2 \theta=8.8^{\circ}\right)$ persisted even after the sample had been heated at $950^{\circ} \mathrm{C}$ although it decreased considerably. Peak area measurements revealed that about $12 \%$ of muscovite survived calcination at $950{ }^{\circ} \mathrm{C}$. Molecular changes during dehydroxylation were also examined with infrared emission spectra (FTIR), confirming decrease in the absorption peaks at 3600-3700 (OH stretch), however peak did not disappear totally indicating only a partial transformation.

The chemical composition and specific surface of the calcined mine waste mud is shown in Table 1. The figures clearly show that mine waste mud consists essentially of silica and alumina, contaminated with arsenic and sulphur
Table 1

Chemical composition and specific surface

\begin{tabular}{lc}
\hline Constituents $(\%)$ & Mine waste mud \\
\hline $\mathrm{SiO}_{2}$ & 53.48 \\
$\mathrm{Al}_{2} \mathrm{O}_{3}$ & 16.66 \\
$\mathrm{Fe}_{2} \mathrm{O}_{3}$ & 12.33 \\
$\mathrm{~K}_{2} \mathrm{O}$ & 7.65 \\
$\mathrm{Na}_{2} \mathrm{O}$ & 0.62 \\
$\mathrm{MgO}$ & 1.27 \\
$\mathrm{SO}_{4}$ & 3.10 \\
$\mathrm{TiO}_{2}$ & 1.39 \\
$\mathrm{As}$ & 1.28 \\
Other minor oxides & 2.22 \\
Blaine fineness $\left(\mathrm{m}^{2} / \mathrm{kg}\right)$ & 357 \\
\hline
\end{tabular}

and with a high content of iron and potassium oxide. Although it's known that iron oxide contributes to the strength of Portland cement it is still and open question if iron also contributes to geopolymerization. The $\mathrm{SiO}_{2} /$ $\mathrm{Al}_{2} \mathrm{O}_{3}$ atomic ratio is 5.5 higher than the one suggested by Davidovits of about 2 for making cement and concrete however, the final $\mathrm{SiO}_{2} / \mathrm{Al}_{2} \mathrm{O}_{3}$ atomic ratio in the hardened binder depends mainly on the reactivity of Al-Si because not all the silica and alumina are reactive so one can not expect the same $\mathrm{Si} / \mathrm{Al}$ ratio in the final hydration product as the one present in the original precursor material. Indeed most of the Al-Si materials cannot even supply sufficient $\mathrm{Si}$ in alkaline solution to start geopolymerization, this explains why they need extra silica provided in solution by waterglass, which influences the $\mathrm{Si} / \mathrm{Al}$ ratio of the hardened binder.

Mine waste Blaine fineness is low but is in the range of the most used slag based alkaline binders. Despite the fact that increase fineness led to increase reactivity that can be overcome by using higly alkaline-silicate activators.

Table 2 shows gradation and physical characteristics of aggregates. Limestone and granitic coarse aggregates have the same Faury maximum dimension (9.52) and similar fineness modulus respectively 5.5 and 5.2. Schist sand has

Table 2

Gradation and physical characteristics of aggregates

\begin{tabular}{lccc}
\hline & \multicolumn{3}{l}{ Cumulative percentage retained } \\
\cline { 2 - 4 } & Schist (SC) & Limestone (LS) & Granite (GR) \\
\cline { 2 - 4 } & Sand & Coarse aggregate \\
\hline $9.5 \mathrm{~mm}$ & 0 & 0 & 0 \\
$4.76 \mathrm{~mm}$ & 0 & 62.9 & 35.4 \\
$2.38 \mathrm{~mm}$ & 0.9 & 89.1 & 91.5 \\
$1.19 \mathrm{~mm}$ & 28.3 & 99.3 & 97.2 \\
$590 \mu \mathrm{m}$ & 62.2 & 99.4 & 98.5 \\
$297 \mu \mathrm{m}$ & 88.8 & 99.4 & 99.2 \\
$149 \mu \mathrm{m}$ & 98.7 & 99.7 & 99.4 \\
$74 \mu \mathrm{m}$ & 99.8 & 99.8 & 99.6 \\
Dust content $(<74 \mu \mathrm{m})$ & 0.2 & 0.2 & 0.4 \\
Fineness modulus & 2.78 & 5.5 & 5.2 \\
Max. dimension $(\mathrm{mm})$ & 2.38 & 9.52 & 9.52 \\
Water absorption $(\%)$ & 0.9 & 0.8 & 0.4 \\
Density $\left(\mathrm{kg} / \mathrm{m}^{3}\right)$ & 2703 & 2659 & 2689 \\
\hline
\end{tabular}


a lower maximum dimension (2.78) and a fineness modulus of 2.38 .

\subsection{Mix proportion and strength testing}

In this investigation the mortar was a mixture of aggregates, waste mud, calcium hydroxide, alkaline silicate solution and water. The mass ratio of mine waste mud: activator was 1:1. Calcium hydroxide was used with a percentage substitution of $10 \%$, because it was found that percentage lead to the highest compressive strengths. An activator with sodium hydroxide $(24 \mathrm{M})$ and sodium silicate solution $\left(\mathrm{Na}_{2} \mathrm{O}=8.6 \%, \mathrm{SiO}_{2}=27.8 \%, \mathrm{Al}_{2} \mathrm{O}_{3}=0.4 \%\right.$ and water $=63.2 \%$ ) was used with a mass ratio of $1: 2.5$. Previous investigations showed that this ratio lead to the highest compressive strength results in alkali-activated mine waste mud mortars [22]. Distilled water was used to dissolve the sodium hydroxide flakes to avoid the effect of unknown contaminants in the mixing water. The alkaline activator was prepared prior to use. The sand, mine waste mud and calcium hydroxide were dry mixed before added to the activator, which according to Pinto et al. [19] is the mixing option that leads to the best results. To produce a workable mix extra water has been added as stated by Jahanian and Rostami [25]. The mass ratio of water/ dry solid binder content was $3.6 \%$ in most of the samples, except for samples with an aggregate/binder mass ratio of 1.5 or 1.7. In those cases, the extra water percentages were respectively 7 and $10 \%$. TMWM binders using schist (SC) fine aggregates with an aggregate/binder ratio of 1.5 were named SC - AG/B 1.5. Similarly when limestone (LS) or granite (GR) aggregates were used were named respectively LS - AG/B 1.5 and GR - AG/B 1.5. TMWM mixtures made with $2 \%$ superplasticizer by mass of binder lime and mine waste mud, were named respectively $\mathrm{SC} / \mathrm{SP}$, GR/SP and LS/SP.

Compressive strength data was obtained using $50 \times 50 \times$ $50 \mathrm{~mm}^{3}$ cubic specimens according to ASTM C109 [26] . The fresh mortar was cast and allowed to set at room temperature for $24 \mathrm{~h}$ before being removed from the moulds and kept at room temperature until tested in compression. Compressive strength for each mixture was obtained from an average of three specimens.

\subsection{Workability}

Workability is a property of a freshly mixed binder (mortar or concrete) that determines the ease, with which it can be mixed, placed, consolidated and finished [27]. Neville also mentioned the flowability capacity as an important property related to workability [28]. The study of a binder material related to his deformation and flowability defines is rheology. This term was created by Bingham in 1929 and comes from the greek word "rhein" which means to flow and is used to define the science of deformation and flow of matter [29]. Unfortunately there is no acceptable test which will measure workability, although different tests have been developed providing useful information about workability variations. In the present study workability was assessed by the "flow table" test according to EN 1015-13 [30].

\subsection{Setting time}

The setting time of a binder material is linked to the loss of consistency when the binder changes from a fluid to a rigid state. For practice purposes that time must not be less than the time required to place the binder material. In the present study setting time was evaluated using the Vicat apparatus according to LNEC E329-1979 [31] for OPC pastes. The test uses two different needles respectively for determination of initial and final setting time. Considerations about setting time behavior related to flash setting mixtures during mix design studies reported elsewhere [22] were also made.

\subsection{Unrestrained shrinkage}

Unrestrained shrinkage used prismatic specimens measuring $40 \times 40 \times 160 \mathrm{~mm}^{3}$ and was determined according to LNEC E398-1993. The procedure is as follows:

The specimens are removed from molds $24 \mathrm{~h}$ after being mixed and placed, then they are wrapped with perspex paper. Other authors used aluminum paper, having reported the formation of hydrogen gas bubbles due to a reaction between the aluminum and the alkalis from the mortar [32]. Unrestrained shrinkage readings were made every hour in the first $10 \mathrm{~h}$, every $3 \mathrm{~h}$ in the next 6 days and twice a day in the remaining days. Unrestrained shrinkage results are presented as defined by Mehta and Monteiro [33] , "microstrain $\left(\times 10^{-6}\right)$ " instead of the linear change length, which does not allow comparisons between different investigation data.

\subsection{Water absorption}

\subsubsection{By immersion at atmospheric pressure}

Water absorption was measured using cylindrical specimens with $10 \mathrm{~cm}$ high and with $5 \mathrm{~cm}$ diameter (Fig. 1). The procedure is as follows:

The specimens were immerse in water at room temperature for $24 \mathrm{~h}$. Weigh the specimens while suspended by a thin wire and completely submerged in water and record $W_{\text {im }}$ (immersed weight). Remove the specimens from water and allow water to drain for $1 \mathrm{~min}$ by placing them on a wire mesh, removing visible surface water with a damp cloth; weigh and record as $W_{\text {sat }}$ (saturated weight). Then, dry all specimens in a ventilated oven at $105^{\circ}$ for at least $24 \mathrm{~h}$ and two successive weightings at intervals of $2 \mathrm{~h}$ show an increment of loss not greater than $0.2 \%$ of the last previously determined weight of the specimen. Record the weight of the dried specimens as $W_{\text {dry }}$ (oven-dry weight). 

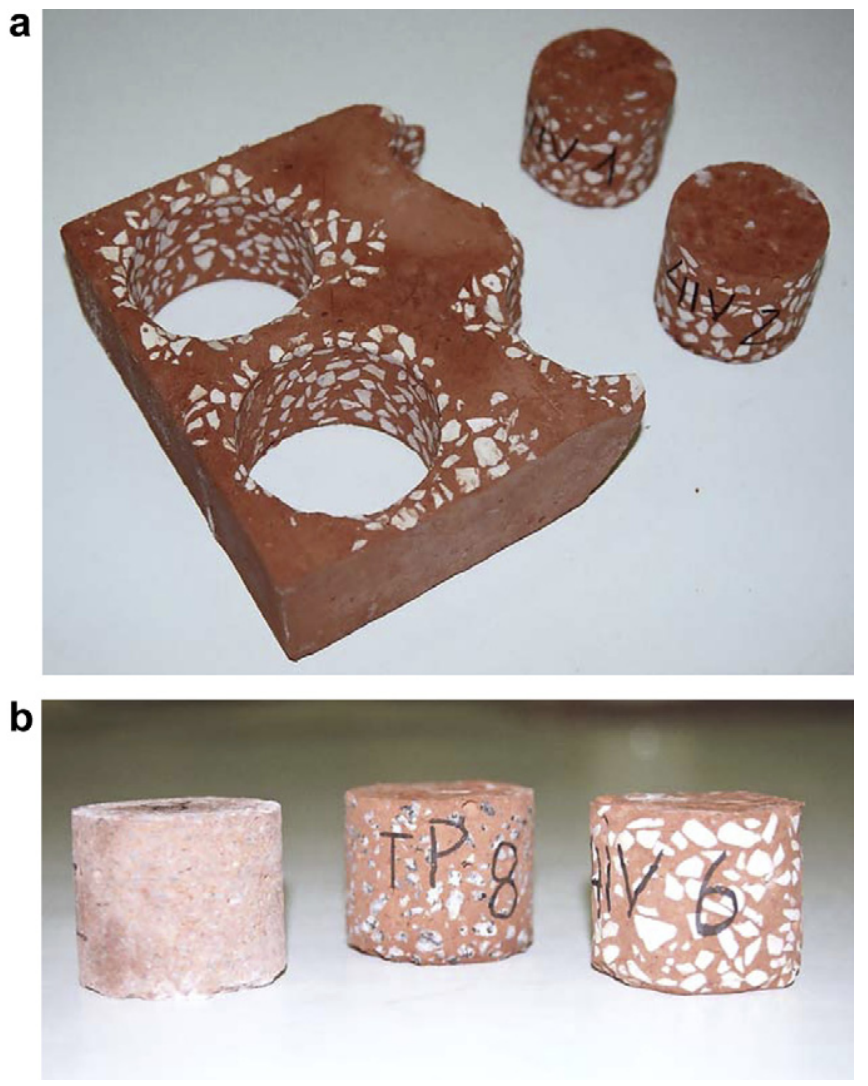

Fig. 1. Specimens for water absorption test.

Absorption is determined as:

$A(\%)=\frac{W_{\text {sat }}-W_{\text {dry }}}{W_{\text {sat }}-W_{\text {im }}} \times 100$

\subsubsection{Capillarity water absorption coefficient}

Capillarity water absorption was carried out using prismatic specimens with $40 \times 40 \times 160 \mathrm{~mm}^{3}$. The test consists in placing the specimens in a container with enough water to maintain one of the sides of the sample immersed. The four vertical sides of the specimens were covered with an epoxy coating to ensure a one-dimensional capillary rise. This test is carried on according to LNEC E393 [34]. Water absorption of the samples have been measured after 3,6, 24,48 and $78 \mathrm{~h}$. Capillarity water absorption coefficient is the slope of the $\Delta$ weight/specimen area versus $t^{1 / 2}$ graph and was determined by using the least squares analysis.

\subsection{Static modulus of elasticity}

The static modulus of elasticity was determined according to ASTM C469 [35] and LNEC E397-1993 [36] using prismatic specimens with $40 \times 40 \times 160 \mathrm{~mm}^{3}$ cured at room temperature during 56 days. The specimens were tested in uniaxial compression at a constant rate of loading of $0.2 \mathrm{MPa} / \mathrm{s}$. A portable data logger was used to record the load and strain readings. The deformation measurements were made using two Linear Variable Differential Trans- formers (LVDTs) located at diametrically opposite locations on the surface of the specimen. The test consisted of applying an initial cycle of loading and unloading, repeated at least twice before the specimen was loaded to the desired level, a maximum of $33 \%$ of their estimated breaking loads and recording the deformations. Three successive load-release cycles were applied. The elastic modulus was determined from the average of two specimens.

\section{Results and discussion}

\subsection{Workability}

It was not possible to evaluate the workability of TMWM mortars using the "flow table" device, due to the viscosity of waterglass which is responsible for the bonding behavior between the mortar and the metallic surfaces of the device. The use of extra water (water added to the mixture after all components have been properly mixed) leads to an increase in the ease of placing operations (without strength loss if the molar ratio water/sodium remain the same) (Fig. 2). The consistency behaviour was rather higher than the one observed by Pinto [18], who mentioned the need of the use of a mason hammer to place in the molds, geopolymeric metakaolin based binders. When TMWM mortar is placed inside the conic mold of the "flow table", it remains bonded to their metallic faces when the mold is lifted, preventing the test to be carried out. This behaviour was not overcome not even when a superplasticizer (SP) was used in the mixtures. The SP led to higher packing and lower porosity specimens, which can be seen from the higher compressive strength behaviour of mixtures with that additive (Fig. 3). One can observe that mixtures with superplasticizer allow compressive strength gains which are influenced by the aggregate type, $19 \%(\mathrm{SC}), 18 \%(\mathrm{GR})$ and $33 \%(\mathrm{LS})$. The strength gain is maximum with $2 \%$ of superplasticizer by mass of binder (calcined waste mud and calcium hydroxide). However, this strength gain is only partially explained by the low porosity due to increase packing, because as the superplasticizer

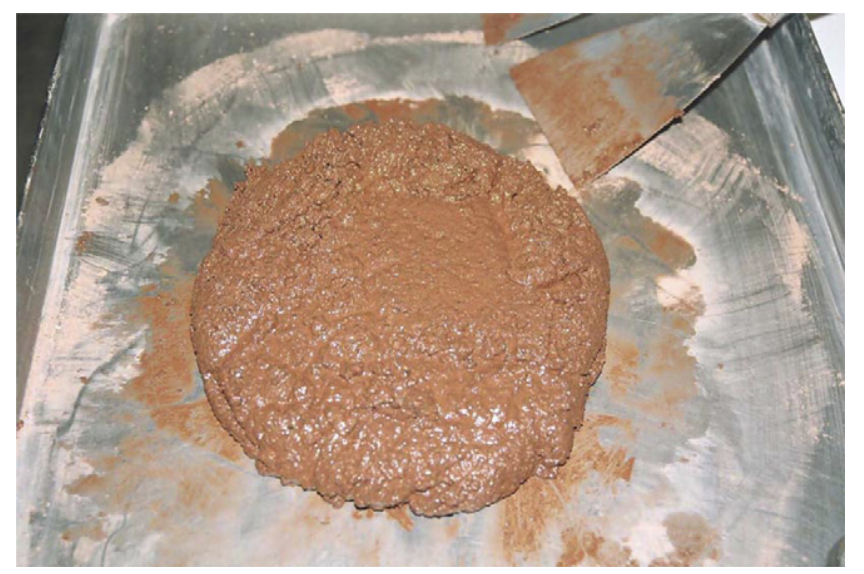

Fig. 2. Fresh TMWM mortar. 

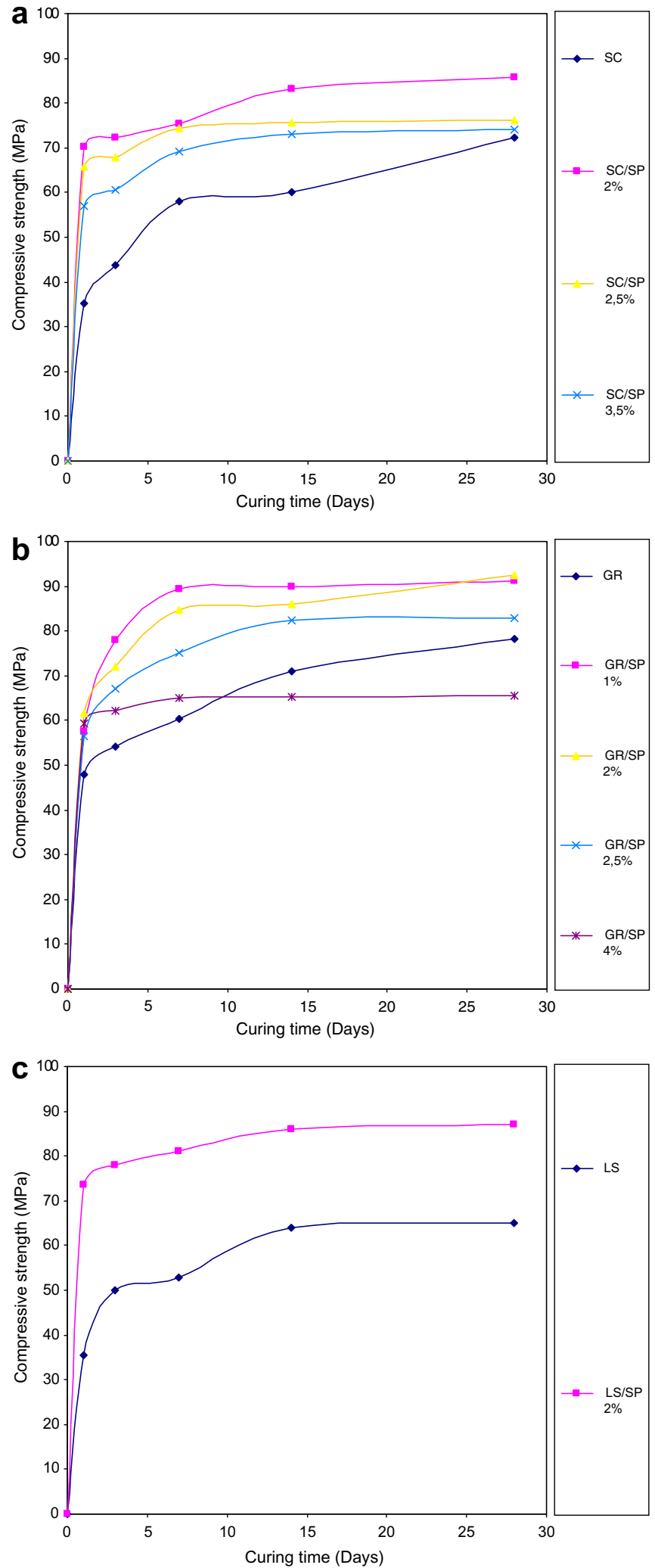

Fig. 3. Influence of superplasticizer content on the compressive strength of TMWM mortars according to aggregate type: (a) schist aggregates; (b) granitic aggregates; (c) limestone aggregates.

delays setting time, (which have been observed although not measured) but also confirmed by other authors [37].
This leads to an increase in the amount of dissolved aluminosilicate material and therefore, less unreacted particles and higher strength. So one can see why the strength gain is lower for mortars with schist (SC/SP) and granitic (GR/ SP) aggregates. If strength gain was due only to the packing effect, those two mixtures would have very different strength gains, due to the very different fineness modulus of the aggregates (2.4 versus 5.2). As for the mortar with limestone aggregates (LS-SP), those aggregates have the same fineness modulus as granitic aggregates, so the differences in strength gain can only be due to the setting time delay effect. In alkali activated mixtures calcium shortens setting time, so the delay effect of the superplasticizer has the higher influence in the mortar with calcium based aggregates.

TMWM mixtures with a superplasticizer percentage above $2 \%$ lead to lower compressive strength, due to excessive setting time delaying effect and electric repulsive forces induced by the superplasticizer. That is in agreement with experimental observations related to a "disconnected" effect in the binder which led to uneasy placement. Although the obstacles in the evaluation of workability performance, experimental observations during mix design studies reported elsewhere [22] show that property is influenced by waterglass/sodium hydroxide mass ratio. Mixtures with a sodium hydroxide concentration of $6 \mathrm{M}$ and waterglass/sodium hydroxide mass ratio between $2: 1$ and 1.5:1, had almost fluid consistency. However, the mixtures with a sodium hydroxide concentration of $16 \mathrm{M}$ and waterglass/sodium hydroxide mass ratio between 3:1 and 2.5:1, were very dry and not workable. That behaviour is due to the viscosity of waterglass and also to an increase in solid content for higher sodium hydroxide concentration mixtures. The former can be overcome using lower sodium hydroxide concentration to dissolved aluminosilicate mine waste mud, if after calcination grinding operations took place in order to obtained a higher Blaine fineness, or if a flash calcination furnace were used, keeping the original Blaine fineness. Concerning the waterglass, there is no way to avoid the unwanted effects related to is viscosity, with the exception of using powder sodium silicate as reported by other authors [38]. However that form is known to led to lower strength performances [39].

\subsection{Setting time}

The setting time (ST) for a TMWM paste with a percentage substitution of waste mud for $10 \%$ of calcium hydroxide, a waterglass/sodium hydroxide mass ratio of 2.5 and a sodium hydroxide concentration of $24 \mathrm{M}$ was respectively 125 and $145 \mathrm{~min}$ for initial and final setting time. This ST is rather higher than the one reported by other authors [18], who mentioned an initial ST of $28 \mathrm{~min}$ for alkali activated metakaolin with the same percentage of calcium hydroxide. However one must consider the fact that metakaolin is a more reactive aluminosilicate material due to its high geologic purity and also higher 
reactive aluminosilicate phases. That explains why the alkali activation of TMWM can only be possible by the use of soluble silica (waterglass) and with high concentration of sodium hydroxide. Besides, the use of extra water to increase the workability of the mixtures may explain part of the ST delay. Furthermore, the ST may also be influenced by the moment when the extra water is added to the mixture. Depending on that particular time, different amounts of dissolved aluminosilicate particles will be in the mixture.

The ST for mortars with superplasticizer have also been analyzed (composition SC/SP with schist sand, sand/binder mass ratio $=1.5$ ) being respectively 70 and $75 \mathrm{~min}$ for initial and final ST. The usual ST delay associated to the use of superplasticizers and reported by Puertas and Palácios [37] would mean that lower STs were expected if no superplasticizer had been used. This means that contrary to OPC binders for which the paste ST gives a good estimation of ST for concrete mixtures, in the case of alkali activated based binders such estimation is not possible.

During the mix design studies, reported elsewhere [22], it was been observed that some mixtures could not be placed due to flash setting problems. From those observations it can be stated that the use of mixtures with a waterglass/ sodium hydroxide mass ratio $=1.5$ is not possible for a sodium hydroxide concentrations above $8 \mathrm{M}$, no matter how the calcium hydroxide percentage substitution is. For a waterglass/sodium hydroxide mass ratio $=2$, only mixtures with a sodium hydroxide concentrations above $12 \mathrm{M}$ and calcium hydroxide percentage substitution above $5 \%$ led to flash setting problems (Table 3). This means that the most important parameter responsible for flash setting is not so much the calcium hydroxide percentage substitution, but the waterglass/sodium hydroxide mass ratio, confirming that waterglass acts as a ST delayer. So it can be said that ST for TMWM binders is influenced by several parameters, among them the aggregates content. So the setting behaviour of TMWM pastes has little relevance in

Table 3

Flash setting (FS) in mixtures made previously [22]

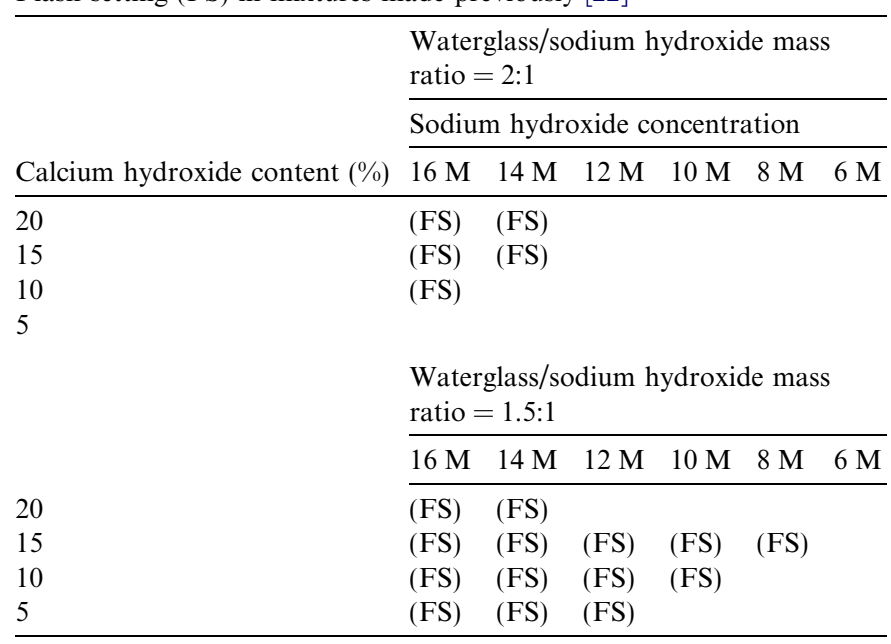

order to estimate the mortar ST. For mortars the use of traditional penetrating devices is not recommended due to the influence of the aggregates and also to the viscosity of the mix, so it is suggested that ST should be evaluated using ultrasonic devices as reported by Lee et al. [40].

\subsection{Unrestrained shrinkage}

Unrestrained shrinkage (US) for TMWM binders is shown in Fig. 4. Generally speaking, shrinkage behaviour is lower than the one observed by Pinto [18] that used alkali activated metakaolin based binders, in similar experimental conditions, having reported US results between 500 and 840 microstrain. That does not mean TMWM binders have lower US. In fact as TMWM binders achieve, after just one day, the same strength level as the one reported by Pinto after 7 days, it means they should have higher US. But unfortunately, as the apparatus only measures shrinkage $24 \mathrm{~h}$ after the mixtures were cast, it misses an important part of US deformation, that may take placed between the time when setting occurs until the specimens were removed from the molds and place in the device. That hypothesis can only be confirmed using a test device that could measure US deformation since the beginning of setting, something that cannot be done with the Vicat penetration test which is currently used for OPC technology, where the shrinkage deformation in the first $24 \mathrm{~h}$ is disregarded [41].

The US data shows a different behaviour for TMWM mortars with an aggregate/binder mass ratio between 1.0 and 1.5 and the ones with the equivalent 0.5 , which have higher shrinkage than the pastes. The US data follows an evolution pattern similar to compressive strength which is determined by the aggregates content and reactivity (Fig. 5).

As the aggregates percentage used in the mortars is much lower than for concretes, i.e mortar aggregate/binder mass ratio is below 2.0 versus between 4 and 5 for concrete, it follows that aggregates act as a set of inclusions trapped

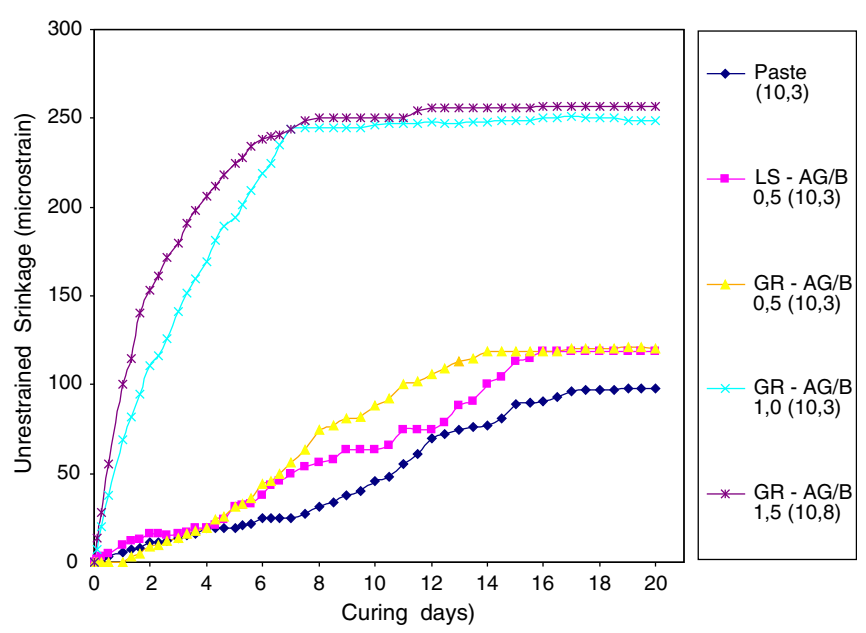

Fig. 4. Unrestrained shrinkage in TMWM binders. 


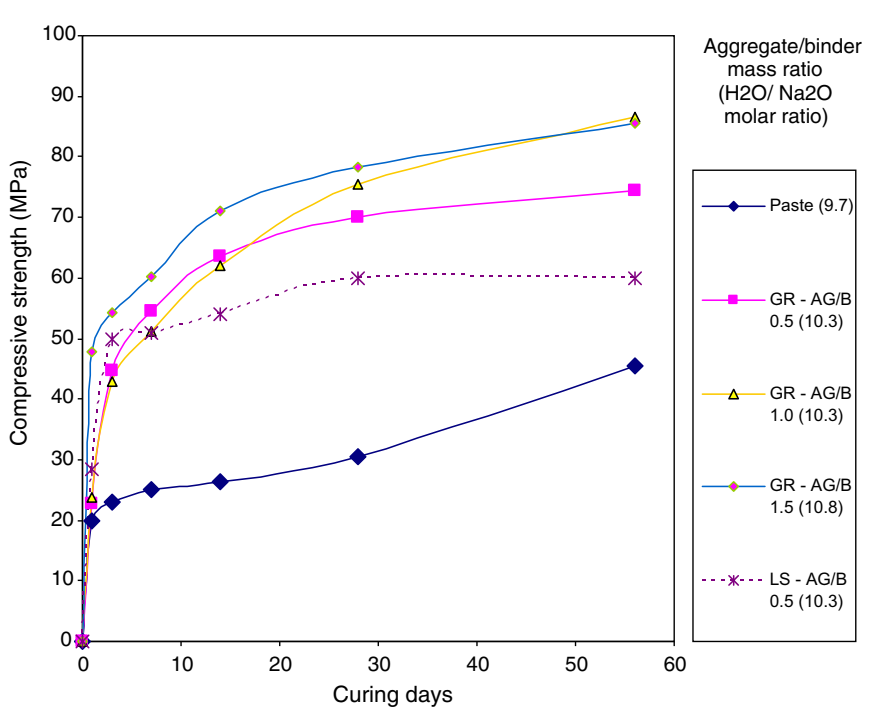

Fig. 5. Compressive strength of some TMWM mixtures.

in a continuous paste matrix and do not form a rigid skeleton which help to diminish US deformation [28,42]. So increasing aggregate content in terms of aggregate/binder mass ratio from 0.5 to 1.5 is not enough to achieve a US reduction. Besides the volume change associated to the shrinkage behaviour is also dependent from the mass of specimens, i.e the US will be higher for lower mass and higher porosity. So the US data reported by Pinto [18] must be analyzed according to the porosity of his specimens $8.3 \%$ and $9.0 \%$, respectively for water absorption by immersion and vacuum water absorption compared to the water absorption by immersion between $2.1 \%$ and $3.4 \%$ for TMWM binders. Furthermore, as the test has been carried out with the isolation of specimens with a perspex film to avoid the evaporation of water, the measured shrinkage is the due to hydration reaction (autogenous shrinkage), so it is necessary that in future work the drying shrinkage of TMWM binders can be evaluated.

\subsection{Water absorption}

\subsubsection{By immersion at atmospheric pressure}

For the determination of water absorption by immersion (WAI) of TMWM mortars, three mixtures corresponding to three types of aggregates (schist, granite and limestone) with the same aggregates/binder mass ratio and with $2 \%$ of superplasticizer were used. The WAI data is the average of four specimens and are shown in Table 4.

Table 4

Water absorption by immersion at atmospheric pressure (WAI)

\begin{tabular}{llc}
\hline Mixture & WAI $(\%)$ & Coefficient of variation CV (\%) \\
\hline SC/SP - AG/B 1.5 & 2.5 & 2.4 \\
LS/SP - AG/B 1.5 & 3.4 & 17.6 \\
GR/SP - AG/B 1.5 & 2.1 & 4.8 \\
\hline
\end{tabular}

For mixtures with schist and granitic aggregates WAI is not much different, contrary to WAI of the mixture with limestone aggregates. However, the WAI of those mixtures had a coefficient of variation of $17.6 \%$, which means they are not very accurate. The WAI data are very similar to the one reported by Wang [43] for vacuum water absorption, but lower than the ones observed by Pinto [18] with $9 \%$, however this author used very dry mixtures and felt the need to use a mason hammer in order place them into the molds, which explains the higher water absorption result.

The absence of a valid statistic relationship between compressive strength and WAI for TMWM mortars doesn't mean compressive strength is not influenced by superficial porosity (Fig. 6), only that the number of results are not sufficient to predict that relation. The water absorption data reported by Pinto [18] when analyzed together with the TMWM binder WAI data (Fig. 7), seems to indicate a valid statistic relationship with compressive strength, helping to explain the lower resistance achieved by his alkali activated metakaolin based specimens.

As for the water absorption data reported by Shi [44] although they seem to present a relationship with compressive strength, they present differences to TMWM mortars

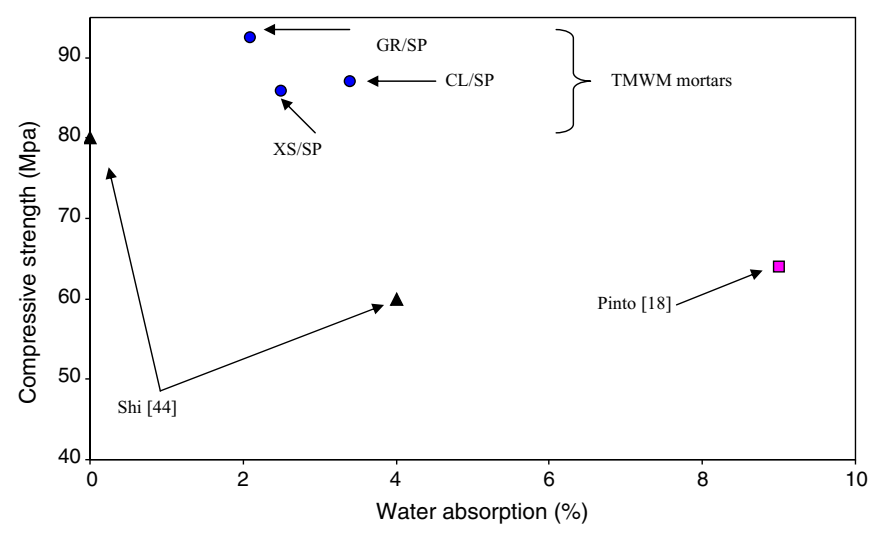

Fig. 6. Water absorption by immersion versus compressive strength.

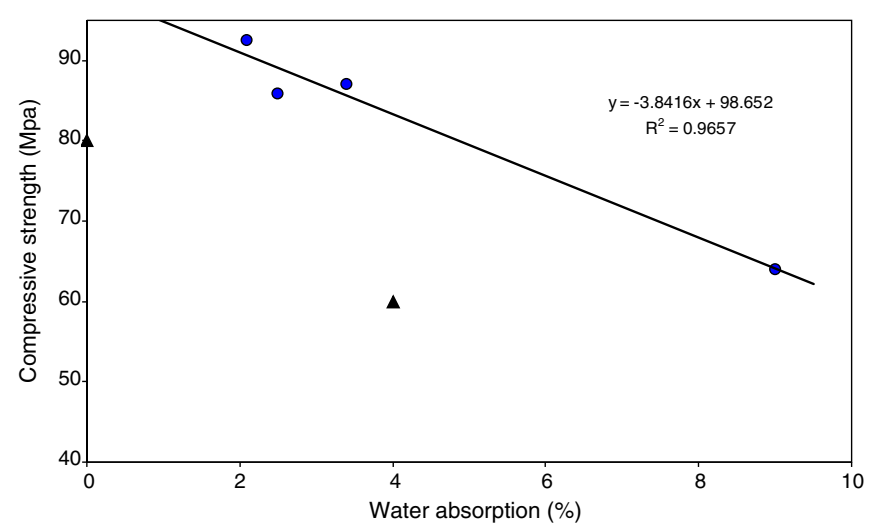

Fig. 7. Water absorption by immersion versus compressive strength, when joining TMWM and Pinto results. 
that could be explain by the fact that this author has not used waterglass, as it is known that this activator usually leads to lower and less coarse porosity.

\subsubsection{Capillarity water absorption coefficient}

The capillarity water absorption coefficients (CWAC) in terms of $\left(\mathrm{g} / \mathrm{cm}^{2}\right)$ are shown in Table 5 . It can be seen the several mixtures have similar CWAC, which makes sense since they have the same mass of aggregates, which have much lower CWAC. Torgal and Castro Gomes [45] reported CWAC between 0.005 and $0.0007 \mathrm{~g} / \mathrm{cm}^{2}$ for granitic and limestone rocks, so it means capillarity water absorption of the TMWM specimens is mainly influenced by the capillarity water absorption of the paste. Besides if a porous and permeable aggregate-paste interface exists, it would be expected that the mixture $(\mathrm{SC} / \mathrm{SP}-\mathrm{AG} / \mathrm{B}$ 1.5) would present a much higher CWAC due to their lower dimension aggregates.

As for the (GR/SP - AG/B 1.5) mixture which presents the highest CWAC that is of difficult explanation because, having been made with a superplasticizer and, therefore, having better compressive strength than the equivalent without that additive (GR - AG/B 1.5) due to higher packing, it should have lower CWAC.

Pinto [18] reported a rather higher CWAC of $0.099 \mathrm{~g} /$ $\mathrm{cm}^{2}$ that he justifies with the possible formation of zeolitic channels. One must consider that he had reported a higher autogenous shrinkage, so that may explain part of the capillarity absorption behaviour.

Table 5

Capillarity water absorption coefficients (CWAC)

\begin{tabular}{lll}
\hline Mixture & CWAC $\left(\mathrm{g} . \mathrm{cm}^{2}\right)$ & Coefficient of variation C.V (\%) \\
\hline SC/SP - AG/B 1.5 & 0.012 & 0.9 \\
GR - AG/B 1.5 & 0.013 & 0.8 \\
LS/SP - AG/B 1.5 & 0.012 & 1.2 \\
GR/SP - AG/B 1.5 & 0.015 & 1.6 \\
\hline
\end{tabular}

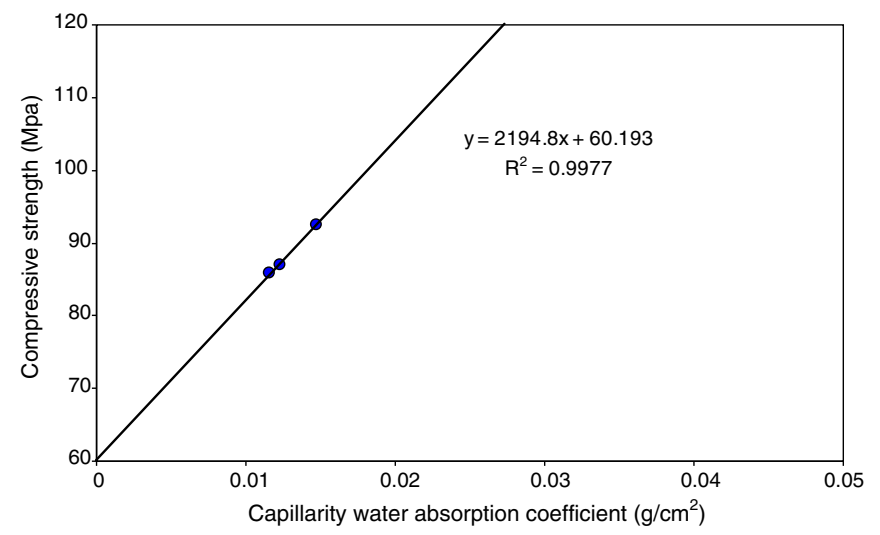

Fig. 8. Capillarity water absorption coefficients versus compressive strength for TMWM mortars.
For TMWM mortars a valid statistic relationship between compressive strength and CWAC was obtained (Fig. 8), meaning strength is influenced by capillarity pores.

\subsection{Static modulus of elasticity}

The static modulus of elasticity (SME) of TMWM mortars are shown in Table 6:

The SME allows to separate the elasticity behaviour of the mixture with granitic aggregates (GR) from the ones with schist (SC). To the same mass amount of aggregates different static modulus of elasticity were obtained (the SME of mixture with granitic aggregates is $85 \%$ of mixture with schist aggregates). That is probably related to aggregate dimension, as a higher dimension and a less volume led to lower SME. For mixtures with granitic aggregates, an increase of $100 \%$ in aggregate amount lead to $14.5 \%$ higher SME.

The SME data are similar to the one obtained by others [18,46-49]. That can be explained by the influence of the aggregates. In fact some authors considered aggregates to be the most important parameter concerning OPC modulus of elasticity [50-52].

While Hardjito et al. [46] and Pinto [18] measured SME in concrete specimens, Duxson [47], Wang [48] and Kirschner and Harmuth [49] evaluated the SME for pastes, which may explain their strangely lower results. Previous investigations on TMWM binders with SEM/EDS microanalysis led to the following data; $\mathrm{Si} / \mathrm{Al}=3.3$ for $(\mathrm{GR}-\mathrm{AG} / \mathrm{B} 1.5)$ and $\mathrm{Si} / \mathrm{Al}=3.2$ for $(\mathrm{XS}-\mathrm{AG} / \mathrm{B} 1.5)$.

The investigations done by Davidovits [53] using high purity alkali activated metakaolin show a decrease in $\mathrm{SME}$, for increase $\mathrm{Si} / \mathrm{Al}$ molar ratio above 3 . This has some confirmation in the work of Fletcher et al. [54], who also

Table 6

Static modulus of elasticity (SME)

\begin{tabular}{llll}
\hline Mixture & SC - AG/B 0.75 & GR - AG/B 0.75 & GR - AG/B 1.5 \\
\hline SME $(\mathrm{GPa})$ & 34.9 & 29.7 & 34.0 \\
\hline
\end{tabular}

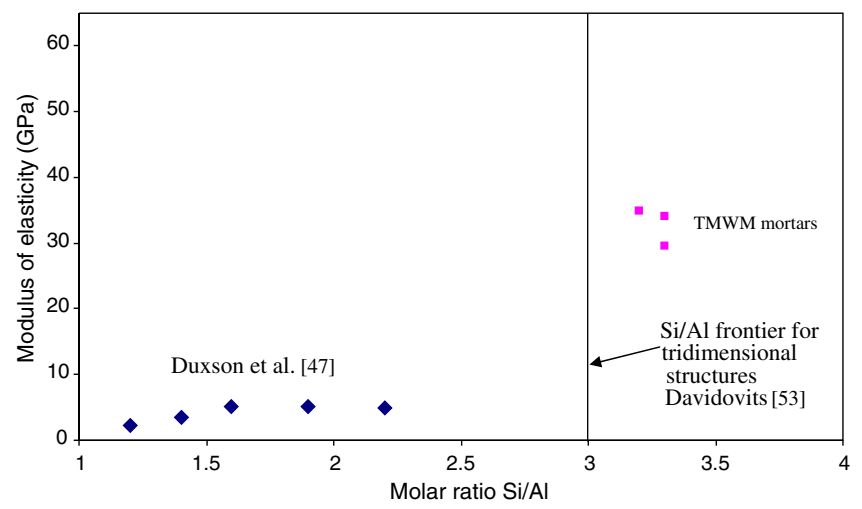

Fig. 9. Modulus of elasticity versus molar ratio Si/Al. 
used alkali activated metakaolin and stated that decrease only happens to an increase in $\mathrm{Si} / \mathrm{Al}$ molar ratio above 24. The SME data obtained for TMWM binders do not confirm the $\mathrm{Si} / \mathrm{Al}$ limits proposed by Davidovits for tridimensional structures (Fig. 9). It is believed that such behaviour is due to the different aluminosilicate materials used in this work, which may generate different hydration products and different structure formation. On the other hand since not even Fletcher confirms those $\mathrm{Si} / \mathrm{Al}$ limits, it seems that they must be considered just as information data.

It was not possible to define the relations $\mathrm{SME} / \mathrm{Si} / \mathrm{Al}$ molar ratio in the work of Pinto [18] and Hardjito [46] since those authors did not mention the $\mathrm{Si} / \mathrm{Al}$ molar ratio of the obtained reaction products, which is not the same as the one of the aluminosilicate material, because not all the síli$\mathrm{ca}$ and aluminum are reactive and also the fact that they used waterglass influences that parameter.

Concerning the statistic relationship between SME and compressive strength (Fig. 10), it can be seen that literature data related to alkali activated binder pastes are located as a family group in which SME changes very little with increase compressive strength.

On the other hand the literature data for alkali-activated concretes is located as a second family near the data obtained for TMWM binders. The former has higher SME which may be due to a coarser microstructure originated by the use of aluminosilicate material with lower Blaine fineness.

Fig. 11 shows two statistic relationships lines for both family results (compressive strength/SME), but only the first his statistically valid $\left(R^{2}=0.8\right)$. The relationship for the second family only becomes valid $\left(R^{2}=0.96\right)$ when the result obtained by Pinto [18] for alkali activated metakaolin based concrete is removed. For the TMWM mortars it has been concluded that when analyzed with the remaining results of the second family, valid statistic

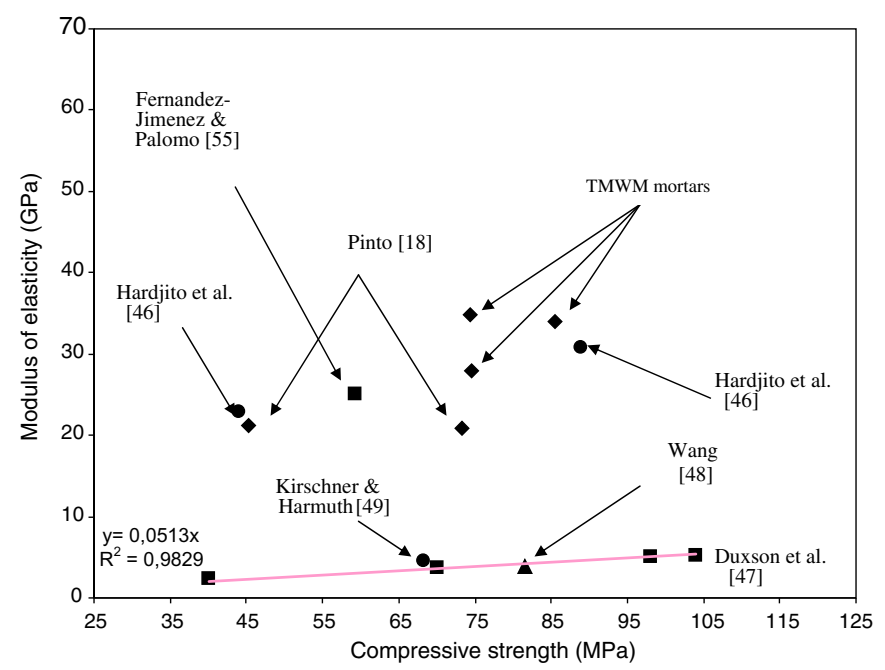

Fig. 10. Relationships between compressive strength and modulus of elasticity.

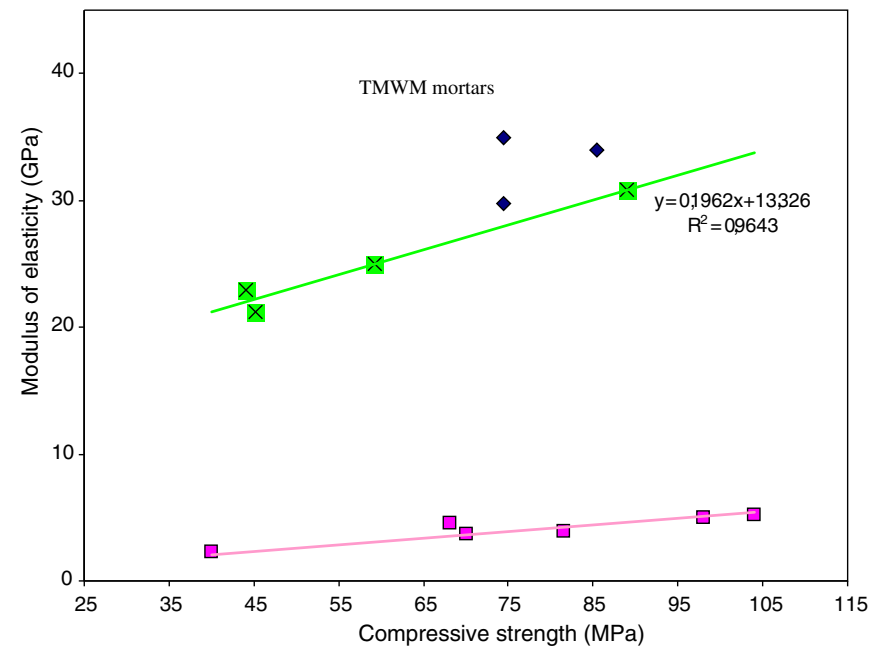

Fig. 11. Relationships between compressive strength and modulus of elasticity. The literature data are joined in two family results.

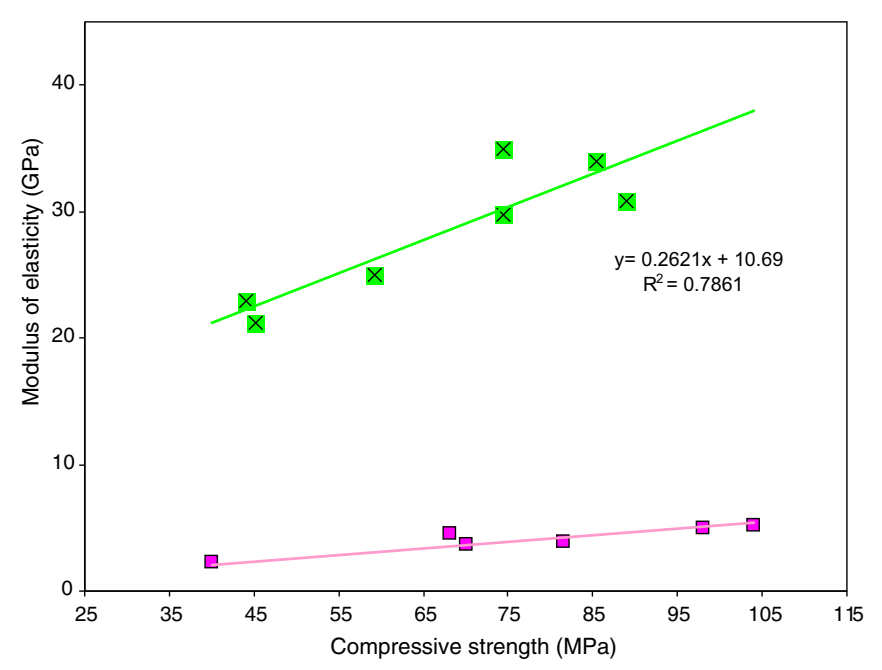

Fig. 12. Relationships between compressive strength and modulus of elasticity. Results for TMWM mortars are gathered with other from alkali activated mixtures.

relationship was obtained $\left(R^{2}=0.79\right)$ which confirms its reliability (Fig. 12).

\section{Conclusions}

The following conclusions can be drawn from this study:

1. With the materials currently used to make TMWM binders it was not possible to assess workability due to the viscosity of waterglass which bonds to metallic surfaces of the "flow table" device.

2. The use of Vicat apparatus to determine setting time is not appropriate for TMWM binders, because it uses paste mixtures and their setting behaviour is different when mortars are used. Besides, it had been observed from flash setting mixtures that were made previously, that setting time is influenced by sodium hydroxide 
concentration, calcium hydroxide content and even by the waterglass/sodium hydroxide mass ratio. The former being the most relevant parameter, because for the ratio 2.5 there was not any mixture with flash setting.

3. Unrestrained shrinkage of TMWM binders is lower than the one observed for OPC binders, being even lower than some alkali-activated binders. However, the measured shrinkage is influenced by the fact that the strain shrinkage from the moment of placing the mixtures until the moment when specimens where removed from the molds $24 \mathrm{~h}$ later is unknown.

4. Water absorption by immersion is rather low which may be due to the use of mixtures properly packed. Although that test is not the most recommended for the characterization of TMWM binders pore structure and, therefore, the knowledge of the possibility of aggressive media entering inside the binder material. Nevertheless it provides a good estimation of environment exposed porosity. The results also lack porosity dimension and distribution which is a relevant aspect that has not been analyzed.

5. As for capillary water absorption coefficients, the results show that TMWM has good performance concerning the ingress of aggressive media inside the binder through capillary absorption transport mechanism. Results also show relevant statistic correlation between capillary water absorption and compressive strength.

6. TMWM static elastic modulus of elasticity is in agreement with the one obtained by other authors. The hypothesis related to the decrease in static modulus of elasticity due to the use of high $\mathrm{Al} / \mathrm{Si}$ alkali activated mixtures was not confirmed. That may be due to the fact that hypothesis may not be applied to binder systems with different aluminosilicate minerals and with the use of a relevant calcium hydroxide content, leading to a different structure formation.

\section{References}

[1] Della Roy M. Alkali-activated cements. Opportunities and challenges. Cement Concr Res 1999;29:249-54.

[2] Davidovits J. Geopolymers: inorganic polymeric new materials. J Thermal Anal 1991;37:1633-56.

[3] Davidovits J. Chemistry of geopolymeric systems, Terminology. In: Proceedings of geopolymer 1999 international conference, France.

[4] Davidovits J. Environmentally driven geopolymer cement applications. In: Proceedings of 2002 geopolymer conference, Melbourne, Australia.

[5] Xu Hua, Deventer JSJ. The geopolymerisation of alumino-silicate minerals. Int J Mineral Process 2000;59:247-66.

[6] Barbosa Valeria F, MacKenzie Kenneth J, Thaumaturgo Clelio. Synthesis and characterisation of materials based on inorganic polymers of alumina and sílica: sodium polysialate polymers. Int $\mathbf{J}$ Inorganic Polym 2000;2:309-17.

[7] Van Jaarsveld JGS, Lukey GC, Van Deventer JSJ. The stabilization of mine tailings by reactive geopolymerisation. Publ Australasian Inst Mining Metall 2000;5:363-71.
[8] Bankowski P, Zou L, Hodges R. Using inorganic polymer to reduce leach rates of metals from brown coal fly ash. Minerals Eng 2004;17:159-66.

[9] Minarikova M, Skvara F. Fixation of heavy metals in geopolymeric materials based on brown coal fly ash. In: Proceedings of the world geopolymer 2005. p. 45-50.

[10] Bakharev AT. Geopolymeric materials prepared using class F fly ash and elevated temperature curing. Cement Concr Res 2005;35: 1224-32.

[11] Mackenzie JD, Brew D, Fletcher R, Nicholson CL, Vagana R, Smucker M. Towards an understanding of the synthesis mechanisms of geopolymer materials. In: Proceedings of the world geopolymer 2005, geopolymer green chemistry and sustainable development solutions. p. 41-4.

[12] Fernandez-Jimenez A, Palomo. Composition and microstructure of alkali activated fly ash binder: effect of the activator. Cement Concr Res 2005;35:1984-92.

[13] Weng L, Sagoe-Crentsil K, Brown T, Song S. Effects of aluminates on the formation of geopolymers. Mater Sci Eng 2005;117:163-8.

[14] Alonso S, Palomo A. Alkaline activation of metakaolin and calcium hydroxide mixtures: influence of temperature, activator concentration and solids ratio. Mater Lett 2001;47:55-62.

[15] Yip CK, Deventer SJS. Microanalysis of calcium silicate hydrate gel formed within a geopolymeric binder. J Mater Sci 2003;38: 3851-60.

[16] Yip CK, Lukey GC, Deventer SJS. The coexistence of geopolymeric gel and calcium silicate hydrate gel at the early stage of alkaline activation. Cement Concr Res, 2005.

[17] Buchawald A, Dombrowski K,Weil M. The influence of calcium content on the performance of geopolymeric binder especially the resistance against acids. In: Proceedings of the world geopolymer 2005, geopolymer green chemistry and sustainable development solutions. p. $35-9$.

[18] Pinto AT. Metakaolin alkali-activated based binders. PhD thesis, University of Minho, Portugal, 2004 [in Portuguese].

[19] Pinto AT, Fernandes P, Jalali S. Geopolymer manufacture and applications - main problems when using concrete technology. In Proceedings of 2002 geopolymer conference, Melbourne, Australia.

[20] Wu Hwai-Chung, Sun Peijang. New building materials from fly ashbased lightweight inorganic polymer. Construct Build Mater, 2005.

[21] Pacheco-Torgal F, Castro-Gomes JP, Jalali S. Geopolymeric binder using tungsten mine waste: preliminary investigation. In: Proceedings of geopolymer 2005 world congress, Saint Quentin, France, 2005. p. 93-8.

[22] Pacheco-Torgal F, Castro-Gomes JP, Jalali S. Effect of mix design on the early age strength of alkali-activated mine waste mud mortars. Construct Build Mater, in press.

[23] Pacheco-Torgal F, Castro-Gomes JP, Jalali S. Effect of aggregates on strength and microstructure of geopolymeric mine waste mud binders. Cement Concr Res; 2007, in press.

[24] Pacheco-Torgal F, Castro-Gomes JP, Jalali S. Thermal treatment of waste mud from Panasqueira mine. Influence of time and temperature of calcination. In: Engineering conference 2005, University of Beira Interior, Covilhã, Portugal [ in Portuguese].

[25] Jahanian S, Rostami H. Alkali ash material, a novel material for infrastructure enhancement. Eng Struct 2001;23:736-42.

[26] ASTM C 109. Compressive strength of hydraulic mortars. In: Annual book of ASTM standards, vol. 04.01. Philadelphia: American Society for Testing Materials (ASTM); 1993.

[27] Neville A, Aitcin P. High performance concrete - an overview. Mater Struct/Mater Construct 1998;31:111-7.

[28] Neville AM. Properties of concrete. 4th and final ed., 1997.

[29] Tattersall GH. The workability of concrete. Slough: Viewpoint Publication; 1976.

[30] EN 1015-13. Methods of test for mortar for masonry: Part 3: Determination of consistence of fresh mortar (by flow table). European Committee For Standardization, August 1999. 
[31] LNEC Portuguese Standard E329. OPC cement. Determination of setting time (1979).

[32] Neto, António Acácio de Melo. Shrinkage study of mortar made with alkali activated slag. Master Thesis 2002, University of São Paulo [in Portuguese].

[33] Mehta PK, Monteiro P. Concrete: structure, properties and materials. PINI, 1994. S. Paulo [in Portuguese].

[34] LNEC Portuguese Standard E393. Concrete: Determination of capillarity water absorption, Lisboa, 1970.

[35] ASTM C 469. Standard test for static modulus of elasticity and Poisson's ratio of concrete in compression. In: Annual Book of ASTM Standards, American Society for Testing Materials (ASTM), 1994.

[36] LNEC Portuguese Standard E397-1993. OPC concrete: Determination of elastic modulus in compression, 1993.

[37] Puertas F, Palacios M. Effect of superplasticizer and shrinkagereducing admixtures on alkali-activated slag pastes and mortars. Cement Concr Res, 2004.

[38] Frank Collins, Sanjayan. Early age strength and workability of slag pastes activated by sodium silicates. Mag Concrete Res 2001;53:321-6.

[39] Wang Shao-Dong, Scrivener Karen, Pratt P. Factors affecting the strength of alkali-activated slag. Cement Concr Res 1994;24: 1033-43.

[40] Lee HK, Lee KM, Kim YH, Yim H, Bae DB. Ultrasonic in-situ monitoring of setting process of high-performance concrete. Cement Concr Res 2004;34:631-40.

[41] Aitcin PC. High performance concrete. Modern concrete technology, vol. 5. E\&FN Spon, 2001.

[42] Tazawa E, Myazawa. Experimental study on mechanism of autogenous concrete shrinkage of concrete. Cement Concr Res 1995;25:1633-8.

[43] Wang Shao Dong. Review of recent research on alkali-activated concrete in China. Mag Concr Res 1991;5154:29-35.

[44] Caijun Shi. Strength pore structure and permeability of alkaliactivated slag mortars. Cement Concr Res 1996;26:1789-99.
[45] Torgal FM, Alves SP, Castro Gomes JP. Influence of physical and geometrical properties of granite and limestone aggregates on the durability of a C20/25 strength class concrete. Elsevier Construct Building Mater 2006;20:1079-88.

[46] Hardjito D, Wallah SE, Sumajouw, Rangun BV. Fly ash based geopolymer concrete, Construction material for sustainable development. Concrete World: Engineering \& Materials. India: American Concrete Institute; 2004.

[47] Duxon P, Provis J, Grant Lukey, Mallicoat Seth, Kriven Waltraud, Deventer Jannie. Understanding the relationship between geopolymer composition, microstructure and mechanical properties. Colloids Surf, 2005.

[48] Hongling Wang, Haihong Li, Fengyuan Yan Yan. Synthesis and mechanical properties of metakaolinite-based geopolymer. Colloids Surf 2005;268:1-6.

[49] Kirschner Andrea, Harmuth Harald. Investigation of geopolymer binders with respect to their application for building materials. Ceramics - Silicaty 2004;48:117-20.

[50] Teychenné DC. The used of crushed rock aggregates in concrete. Garston: Building Research Establishment; 1978.

[51] Zhou FP, Lydon FD, Barr BI. Effect of coarse aggregate on elastic modulus and compressive strength of high performance concrete. Cement Concr Res 1995;25:177-86.

[52] Rashid MA, Mansur MA, Paramasivam P. Correlations between mechanical properties of high strength concrete. J Mater Civil Eng 2002:230-8.

[53] Davidovits J. Chemistry of geopolymeric systems. In: Terminology. Proceedings of 99 geopolymer conference, vol. 1; 1999. p. $9-40$.

[54] Fletcher Ross A, Mackenzie Kenneth JD, Nicholson Catherine L, Shimada Shiro. The composition range of alumino silicate geopolymers. Journal of European Ceramic Society, 2004.

[55] Fernandez Jimenez A, Palomo A. Characterisation of fly ashes. Potential reactivity as alkaline cements. Fuel 2003;82: $2259-65$. 